Send your letters to the editor, British Dental Journal, 64 Wimpole Street, London W1G 8YS E-mail bdj@bda.org

Priority will be given to letters less than 500 words long. Authors must sign the letter, which may be edited for reasons of space

\section{What is scientific evidence?}

Sir, little did I think when I penned my letter to you in November of last year ${ }^{1}$ that it would be published, let alone invoke a reply. ${ }^{2}$ I was simply venting my frustration as to what to say (or not say) to my pregnant patients who have periodontal disease. The letter from Beckett et al. ${ }^{2}$ raised some interesting points. The journal club rejected the paper by Radnai et $a l^{3}$ on both methodology and statistical analysis. The second paper by Moore et al. ${ }^{4}$ was accepted as scientifically valid, however, the journal club could not come to a general consensus as to its clinical validity. At the time of my original letter this was simply an academic argument, however, that has now changed. The front page of the May 2005 edition of Dentistry reported on the case of $\mathrm{Dr}$ Francois Rossouw with regards to the treatment of a TMJ patient (further details in summer 2005 GDC Gazette p. 24). Dr Rossouw was found guilty by the GDC of providing unconventional treatment that was not supported by good scientific evidence. So I am back where I started. What is good scientific evidence? Is it a peer reviewed paper published in a reputable peer reviewed journal? - apparently not. Is it a peer reviewed paper analysed by a journal club and given total approval? apparently not. The current state of play appears to be a peer reviewed paper given a majority vote by a journal club.

So let's go back to my original dilemma. A pregnant patient comes to see me who shows signs of periodontitis. I advise her that I think it is important to treat her periodontal condition to both save her teeth and also reduce the risk of a preterm or under weight birth. This information causes her concern and she complains to the GDC. Reducing the risk of a pre term or under weight birth by the use of a Cavitron can be considered as unconventional therapy. The GDC ask me for my scientific proof so I quote Radnai et $a .^{3}$ (along with Moreu et al., ${ }^{5}$ Khaler et al. ${ }^{6}$ Martin et al. ${ }^{7}$ and Dortbudack et al. ${ }^{8}$ ) The GDC call Dr Beckett as an expert witness to show that the paper by Moore et $a l .{ }^{4}$ proves I am wrong and hence guilty as charged.

Now let us take scenario ${ }^{2}$. I do not advise the patient of my concerns and she now proceeds to have a pre-term or low weight baby. The mother then trawls the internet and finds the paper by Radnai et al. ${ }^{3}$ and again complains to the GDC that I did not advise her appropriately. My defence is then to ask Dr Beckett to come to my defence along with the rest of the journal club.

I believe we therefore need a clear definition of what constitutes evidence based dentistry and to have this clarified by the GDC.

\section{J. Ahearne}

Poole

1. Ahearne J. Evidence based dentistry. Br Dent J 2004; 197: 154 .

2. Beckett H et al. Journal clubs. Br Dent J 2005; 198: 629

3. Radnai M et al. J Clin Periodontal 2004; 31: 736-741.

4. Moore et al. Br Dent J 2004; 197: 251-258.

5. Moore et al. J Clin Periodontal 2005; 32: 622-627.

6. Khader et al. J Periodonta/2005; 76: 161-165

7. Martin et al. J Clin Periodontal 2005; 32: 174-175.

8. Dortbudack et al. J Clin Periodonta/ 2005; 32: 45-52

Antony Townsend, Chief Executive and Registrar of the GDC responds: Thank you for the opportunity to respond to this letter. While it is not appropriate for me to comment on the details of Mr Rossouw's case, it may be helpful to explain some general principles.

GDC Professional Conduct Committee cases are considered by an independent panel of individuals. Each case is different and has to be considered on its own individual merits. Panel members must consider all the evidence presented to them and make a reasoned decision on the dentist's fitness to practise. This will often involve very complex issues of judgement. The dentist facing the charge has the opportunity at the hearing to demonstrate their justification for their actions, measured against the principles we set out in the applicable GDC standards guidance (now Standards for Dental Professionals). As the article on page 25 of the summer edition of the GDC Gazette (to which $\mathrm{Mr}$ Ahearne refers) demonstrates, the panel

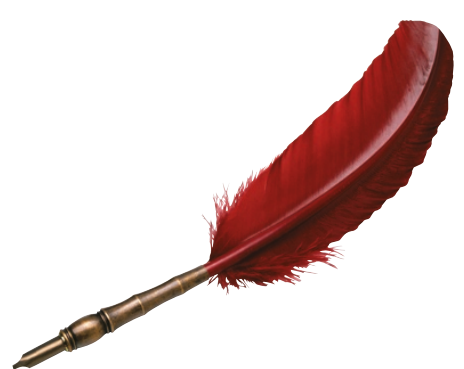

found Mr Rossouw guilty of serious professional misconduct in relation to a series of factors, not simply the selection of one method of treatment.

I do not think that it would be helpful for the GDC to attempt to set down precise rules about what constitutes informed evidence based opinion in all circumstances: a professional regulator should establish broad principles, not seek to micro-manage the individuals whom it regulates. Standards for Dental Professionals reminds dental professionals that they should 'Provide a good standard of care based on available up-to-date evidence and reliable guidance'. Dental professionals are expected to apply this ethical principle to their decision-making. doi: 10.1038/sj.bdj.4812747

\section{Futile complaints}

Sir, the disquieting letter from Mr Law (BDJ 2005; 199: 3) raises many issues. Without much more detail it is of course difficult for your readers to dismiss the possibility that he is a tiresome vexatious complainer. However, unfortunately his letter rings true, and I would be surprised if most of us did not believe him. It demonstrates the almost complete helplessness of patients when confronting a possibly inadequate dentist (16 fillings in a single appointment followed by severe pain) and a certainly inadequate complaint scheme. Mr Law's letter shows very clearly that once a practice has rejected a complaint, as happened to him, the administrators of the NHS are either not bothered or incapable of helping. The fact that most of us who work in the GDS could have predicted the feeble and inadequate response of the PCT does not excuse it. Fewer of us have experience of the Health Commission, but if Mr Law's account is accurate, it is not going to be much use to patients. If I were Mr Law I would find the response by Professors Bedi and McGrath even worse. That two such eminent professors could write anything so smug while completely missing the point of Mr Law's letter beggars belief. What is the CDO going to do to make PCTs take this sort 
of complaint seriously? What is he going to do about the Health Commission? It is not very helpful, or even empathetic, to write about a possible complaint scheme for private patients, while the NHS scheme does not appear to serve the needs of patients. $\mathrm{Mr}$ Law successfully navigated a fragmented complaint procedure and still got nowhere.

C. Forsyth

Uppingham

doi: 10.1038/sj.bdj.4812748

\section{The great Harry Davis?}

Sir, in researching the biography of my late father, Thomas Henry Brown (LDS Dunelm, 1929), I have come across the following poem, published in the Medical Gazette in 1929, poking typical student good-natured fun at one of his supervisors:

\section{Friday is my Unlucky Day}

Where is your mirror and probe, my boy, Where is your mirror and probe?

How can you see those buried roots

And wisdoms lurking there?

I've shouted at you before, my lad,

Don't let it occur again.

I'll overdose you with Arsenicalis

If you don't find that mirror and probe.

I come from the wilds of Fenham, my boy,

I am the great -ARRY D-IS!

Harry Davis was presumably born in the late 1800 s and is clearly a larger than life character and well liked. Anything that colleagues can tell me about him would be most welcome. Please contact me at anthony.brown14@ntlworld.com

\section{A. T. Brown \\ Nunthorpe}

doi: 10.1038/sj.bdj.4812749

\section{Lamentable propaganda}

Sir, I read with curiosity the letter written by Professor Avery and his colleagues (BDJ 2005; 198: 756). I currently form a second on-call rota for maxillofacial emergencies that constitutes two staff grades, two associate specialists and one specialist registrar. As such all four "middle grades' are involved in 'more complex surgical procedures'.

Neither myself, nor my consultant colleagues received any questionnaire concerning the scope of practice of staff grades and associate specialists or consultants for that matter. The data produced are necessarily flawed. A not uncommon comment from my consultant colleagues is that they feel they are becoming de-skilled simply because so much trauma is being treated by their trainees or 'middle grades'.

It is perhaps understandable that The British Association or Oral and Maxillofacial Surgeons should seek to influence the General Dental Council in decisions the outcome of which they have a vested interest in, but it does not serve them well that they produce propaganda of this nature. Unfortunately this Association has a lamentable history of ignoring any other needs but that of its consultant body.

I do at least share the sentiment that this information will be useful in the continuing review process.

\author{
R. Bunyan \\ Luton \\ doi: 10.1038/sj.bdj.4812750
}

\section{Piggy in the middle}

Sir, the future of dentistry in the hands of our legislators is unsure. I am not referring to 'PDS' or 'New Contracts'. I am referring to the statutory examination of DSAs. I have no problem with a reasonable qualification which bears relevance to the practicalities of the job. However, if you examine what is being asked of potential DSAs by the City \&t Guilds NVQ you would be amazed.

For example:

- Provide up-to-date information which takes account of the complexity of the decisions which people may need to make.

- Must understand the socio-economic context of people including their disposable income and their relative income.

- Must understand the purpose of structuring one's own action research and developing and implementing these in unstructured ways.

- Understand the meaning of the term 'reflective practitioner' and how one can become more reflective in one's work.

- How one can evaluate realistically the outcomes of one's own action research.

- What are the diverse experiences and perspectives which people bring to any interactions and the benefits of diversity in a multicultural society?

- What are the assumptions and oppressions which surround different groups (such as sexism, racism, ageism, heterosexism, discrimination against those with mental health problems, learning disabilities and physical disabilities) and the ways in which this is built into society and agencies?

We have a lot of part-time workers in dentistry. Why would you bother with taking this level of exam for two days a week? They won't - and we dentists will be 'piggy in the middle' trying to find a way around this potential lack of qualified staff in the future.

Watch this void!

\section{G. Buck}

Storrington

doi: 10.1038/sj.bdj.4812751 